\title{
Hyphenated NMR Methods in Natural Products Research, Part 1: Direct Hyphenation
}

\begin{abstract}
This review describes the current status of the development of techniques combining liquid chromatography and nuclear magnetic resonance and their use in the context of natural products. HPLC-NMR methods have a rapidly growing impact on natural products research by enabling structure determination of natural products directly from small amounts of extracts, i.e., prior to the investment in an often lengthy and laborious preparativescale isolation process. This speeds up extract dereplication and helps to avoid re-isolation of already known extract constituents.
\end{abstract}

Direct HPLC-NMR hyphenation techniques, defined as methods in which NMR spectra are recorded using the HPLC eluate, are described. The recently developed indirect HPLC-NMR method employing an automated solid-phase extraction interface between HPLC and NMR, which replaces the chromatographic solvent with a different solvent for NMR data acquisition, is described in the second part of this review.

\section{Key words}

Nuclear magnetic resonance · liquid chromatography • LC-NMR . HPLC-NMR · hyphenated techniques · dereplication

\section{Introduction}

Natural products are usually extracted as complex mixtures containing many constituents present in widely different concentrations and representing a broad spectrum of physical and chemical properties. Initially, the composition of extracts is often completely unknown. For these reasons, isolation and structure elucidation of individual constituents from such mixtures pose a considerable challenge, requiring a lot of time, labor and costs.

The reason for undertaking an isolation study is very often some sort of biological activity, observed in a bioassay or anticipated from traditional uses. However, a positive pharmacological response by itself is not sufficient to qualify an extract for fractionation work, nor is its absence sufficient to disqualify it (because of inherent difficulties with assaying mixtures and the possibility of detecting false positive or false negative results). Even if a genuine pharmacological response resides in a single and welldefined constituent, it may not merit purification because the constituent is already known, trivial, or otherwise unwanted. Thus, the problem of isolation of pharmacologically active natural products quickly becomes chemical in nature, not only because one must decide about the methods of fractionation and purification (which depend on the chemical properties of the constituent in question), but also because it is desirable to know, as early in the fractionation process as possible, what is being purified. For these reasons, a rapid establishment of a bridge between a confirmed or anticipated biological activity and chemical structure (or at least a general chemical nature) of extract constituents present is a central issue in modern natural products research. The library approach [1], [2] for the discovery of drugs from natural sources also calls for use of targeted isolation procedures that necessitate early access to reliable structural information about extract constituents. 
In fact, seeking information about the chemical nature or identity of compounds present in an extract prior to their isolation is as old as the chemistry of natural products itself, and organoleptic tests and various color reactions have been commonly used in the past. Since identification of compounds directly from a complex mixture can normally be achieved only for the most abundant constituents, there is a need for combining a separation method with a method giving insight into the chemical structure. Hyphenated methods are thus defined as methods combining two or more analytical techniques (usually a separation and a spectroscopic technique) into one integrated technique described by use of a hyphen, as in HPLC-NMR. Although a modern hyphenated technique implies a computer-controlled on-line process, long-known combinations of paper chromatography or TLC with compound-class specific spray reagents may be regarded as classical hyphenated techniques. The introduction of photodiode-array (PDA) detectors providing UV spectra of compounds eluted from chromatographic columns constituted a great advantage compared to single-wavelength UV-VIS detectors, but structural information provided by electronic spectra is quite limited. During recent decades, MS methods combined with GC and more recently with LC (usually implemented as HPLC) had a great impact on natural products research. However, GC-MS is restricted to volatile constituents, and the ionization techniques used in LC-MS usually give information about the molecular ion and the basic fragments only. Thus, only NMR spectroscopy with its broad repertoire of highly sophisticated 2D experiments can be used for making definitive claims about chemical structures of more complex natural products, both new and already described. A brief overview of main hyphenated techniques used in natural products research is shown in Table $\mathbf{1}$

In this article, an overview of theory and applications of hyphenated NMR spectroscopic methods pertinent to or used in the context of natural products is given. Applications not related to natural products, such as those concerned with pharmaceutical analysis or drug metabolism, are not mentioned unless they describe important technical advancements. Part 1 of this review deals with direct HPLC-NMR methods, i.e., methods in which the HPLC system is connected directly to a flow-cell of the NMR spectrometer operating in continuous-flow or stopped-flow mode. The loop-storage technique, which still involves acquisition of NMR data in the solvent used for chromatography, is also described. The recently introduced HPLC-SPE-NMR technique is described in Part 2. Because the vast majority of LC methods hyphenated with NMR spectroscopy are standard HPLC methods, the term HPLC-NMR is used rather than LC-NMR.

\section{Principles of HPLC-NMR}

Today, NMR spectroscopy is certainly the most powerful and versatile technique for structure elucidation of natural products. Its advantage as a HPLC detector resides not only in the fact that full structural and stereochemical information can be obtained (by use of 2D NMR), but also because it is a highly non-selective detection technique $\left({ }^{1} \mathrm{H}-\mathrm{NMR}\right.$ spectroscopy will detect any hydrogen-containing compound present in the HPLC eluate in a sufficient amount regardless of its structure). The interest in combining separation methods with ${ }^{1} \mathrm{H}-\mathrm{NMR}$ spectroscopy arose
Table 1 Overview of main hyphenated techniques used in natural products research

\begin{tabular}{|c|c|c|}
\hline $\begin{array}{l}\text { Hyphenated } \\
\text { technique }\end{array}$ & Principal advantages & Principal limitations \\
\hline LC-PDA & Rapid, easy to use and cheap & $\begin{array}{l}\text { Structural information } \\
\text { provided by UV spectra very } \\
\text { limited }\end{array}$ \\
\hline GC-MS & $\begin{array}{l}\text { Excellent resolving power of } \\
\text { GC, high information content } \\
\text { of electron-impact mass } \\
\text { spectra (EI-MS) }\end{array}$ & $\begin{array}{l}\text { Restricted to volatile } \\
\text { samples; best applicable to } \\
\text { known compounds for which } \\
\text { El-MS fingerprints are } \\
\text { available for automatic } \\
\text { (unsupervised) structure } \\
\text { determination }\end{array}$ \\
\hline LC-MS & $\begin{array}{l}\text { Excellent resolving power of } \\
\text { LC methods, applicable to } \\
\text { non-volatile constituents }\end{array}$ & $\begin{array}{l}\text { Structural information } \\
\text { provided by electrospray } \\
\text { ionization MS limited } \\
\text { (extendable by MS/MS and } \\
\text { high-resolution MS); } \\
\text { ionizability of various } \\
\text { compounds vary greatly }\end{array}$ \\
\hline LC-NMR & $\begin{array}{l}\text { Excellent resolving power of } \\
\text { LC methods; highly non- } \\
\text { selective; full structural infor- } \\
\text { mation in principle available }\end{array}$ & $\begin{array}{l}\text { Lower sensitivity compared } \\
\text { to other LC detectors; } \\
\text { automatic (unsupervised) } \\
\text { structure elucidation still in } \\
\text { infancy }\end{array}$ \\
\hline
\end{tabular}

already at the end of the $1970 \mathrm{~s}$, when the capabilities and potential of this spectroscopic technique had become well recognized [3], [4], [5], [6], [7]. The initial trials used iron magnets, but the advantage of superconducting solenoid magnets was quickly recognized [8], [9]. However, it took almost two decades before the HPLC-NMR combination started to provide competitive results. In addition to the need for appropriately designed flow-cells [10], the principal issues in relation to the use of NMR spectrometers as detectors for liquid chromatography are sensitivity and solvent choice.

NMR is a comparatively insensitive spectroscopic technique, a fact that originates from the small difference between energy levels of atomic nuclei, which leaves only a small population excess of spins occupying the ground state at thermal equilibrium and giving rise to the NMR signal. However, already early ironmagnet spectrometers exhibited sensitivity comparable to that of refractive index (RI) detectors [4], and the sensitivity of commercial NMR instruments improves continuously [11], [12], [13]. Under ideal conditions, the signal-to-noise ratio in NMR is proportional to the $7 / 4$ power of the magnetic field strength. While HPLC-NMR applications at $800 \mathrm{MHz}$ have been reported [14], use of ultra-high field strengths is associated with excessive costs. On the other hand, small-volume (30-120 $\mu$ L detection volume) flow-probes in current use offer a mass sensitivity (signal-tonoise ratio per mass unit) that is much greater than that of traditional NMR probes. Using a $600 \mathrm{MHz}$ magnet, the limit of ${ }^{1} \mathrm{H}$ detection of a compound with MW 500 is roughly 100 ng [15], but micrograms would be required for routine structure elucidation work. The sensitivity of NMR detection increases three- or fourfold by use of probes with cryogenically cooled receiver coils and preamplifiers [12], [16]; the sensitivity gain achieved by cooling these electronic components to about $20 \mathrm{~K}$ is due to the reduced electronic noise. Thus, use of cryogenic probes enables NMR 
spectra to be obtained with $3-4$ times less material during a given data acquisition period, or to reduce the data acquisition time by a factor of 9-16 with the same sample size. Therefore, the current capability of obtaining good quality $1 \mathrm{D}{ }^{1} \mathrm{H}-\mathrm{NMR}$ spectra with sub-microgram amounts and to record ${ }^{1} \mathrm{H}$-detected 2D NMR spectra with microgram quantities is very sufficient for natural products applications, especially when one considers that the method is fully non-destructive and analytical HPLC columns can usually be loaded with several hundred micrograms of extracts. A further decrease of detection limit is expected as a result of continued technology improvements.

An important issue is the solvent used for chromatographic separation, because the problem is not just to detect a given amount of material but also to do so in the dilute solution emerging from an HPLC column. Since most solvents contain hydrogen, they will give rise to an NMR signal much stronger than that of the analyte. Thus, a dynamic range problem of detecting small analyte resonances in the presence of $10^{3}-10^{6}$ times stronger solvent resonances arises, and it is necessary to apply pulse sequences that suppress solvent resonances. Most commonly used solvent-peak suppression pulse sequences are the standard 1D NOESY sequence applying soft pulses on solvent resonances during mixing time and relaxation delay for 1D spectra, and the pulsed field-gradient-based WET sequence (water suppression enhanced through $\mathrm{T}_{1}$ effects) for $1 \mathrm{D}$ and $2 \mathrm{D}$ spectra [17]. It must be emphasized that solvent peak suppression methods only greatly reduce the intensity of solvent resonances, rather than removing them completely. The larger the initial solvent peak, the more difficult it is to suppress it. Moreover, the suppression brings about distortion of the spectral region where the solvent resonances were present, and distorts or removes nearest analyte resonances. In order to avoid problems with very strong and difficult or impossible to suppress solvent resonances, deuterated solvents are frequently used for chromatographic separations. This applies especially to water, which gives a relatively broad and difficult to suppress signal. Therefore, mixtures of $\mathrm{D}_{2} \mathrm{O}$ and $\mathrm{CH}_{3} \mathrm{CN}$ (usually not deuterated because of excessive cost) are the most frequently used solvents for reversedphase $\left(C_{18}\right)$ elution in HPLC-NMR, in gradient as well as isocratic mode. Because deuterated solvents usually contain 99.8 atom \% of deuterium, suppression of the residual solvent signal will still be necessary. Since $1.1 \%$ of the ${ }^{1} \mathrm{H}$ resonance of $\mathrm{CH}_{3} \mathrm{CN}$ consists of ${ }^{13} \mathrm{CH}_{3} \mathrm{CN}$, solvent suppression will be further improved by applying ${ }^{13} \mathrm{C}$ decoupling that collapses ${ }^{13} \mathrm{C}$-satellites in the ${ }^{1} \mathrm{H}$-NMR spectra.

It must be stressed that HPLC separations should be carefully optimized for high column loading and for elution bands that are as sharp as possible. Broad and unsymmetrical peaks diminish the analyte concentration in the eluate and compromise the quality of NMR spectra. The sensitivity of continuous-flow HPLC-NMR experiments will also be limited by the residence time of the analyte in the NMR flow-cell. Short residence times reduce effective lifetimes of a particular excited spin state and increase NMR line-width, depending on a particular ratio between cell volume and flow rate [18], [19], [20]. In order to perform NMR data accumulations that require longer time, such as 2D NMR experiments or $1 \mathrm{D}$ experiments with small amounts of the analyte, the flow must be stopped when the chromatographic peak of interest reaches the NMR cell. In the stopped-flow mode, compounds that still reside within the HPLC column will be broadened by diffusion, which can compromise NMR experiments with the remaining peaks. In order to avoid these problems, peak-storage devices for HPLC-NMR have been introduced. In the following paragraphs the use of various HPLC-NMR schemes to natural products is illustrated.

\section{Continuous-Flow HPLC-NMR}

As already mentioned, limited residence time of the analyte in the NMR flow-cell affects the spectral quality and limits the time available for the acquisition, which restricts the detectable amount of analyte to above $10 \mu \mathrm{g}$ (compounds with MW 300500 ), depending on experimental conditions. Nevertheless, onflow experiments were the first HPLC-NMR experiments to be introduced and are still frequently used to gain an overview of the major metabolites present in an extract. They are rarely used as an isolated HPLC-NMR experiment but usually as an introductory experiment followed by stopped-flow investigations. In an early study (1994), Johnson et al. performed a model on-flow experiment with a mixture of limonoids using a $250 \times 4.6 \mathrm{~mm} \mathrm{C}_{18}$ column and a $500 \mathrm{MHz}$ spectrometer equipped with a $60-\mu \mathrm{L}$ flow-probe [21], and Spring et al. analyzed a crude dichloromethane extract of Zaluzania grayana (Asteraceae) using a similar set-up [22]. Hostettmann and Wolfender reported numerous on-flow HPLC-NMR experiments at $500 \mathrm{MHz}$ [23], [24], [25], [26], [27], [28], [29], [30], [31]. These include analysis of a crude dichloromethane extract of Swertia calycina (Gentianaceae) leading to identification of three major extract constituents [23], identification of two main constituents in a crude dichloromethane extract of Monotes engleri (Dipterocarpaceae) [24], the study of an antioxidant fraction obtained from Orophea enneandra leaves (Annonaceae) [25], analysis of a crude dichloromethane extract of Cordia linnaei (Boraginaceae) [26], detection of isoflavanones in a crude dichloromethane extract of roots of Erythrina vogelii (Fabaceae) [27], investigation of decomposition products of hyperforin [28], analysis of tropane alkaloids from an alkaloid extract of Erythroxylum vacciniifolium (Erythroxylaceae) stem bark [29], and studies on dichloromethane and methanol extracts of Potamogeton (Potamogetonaceae) species [30], [31]. All these studies employed $\mathrm{C}_{18}$ columns and gradients of $\mathrm{CH}_{3} \mathrm{CN}$ in $\mathrm{D}_{2} \mathrm{O}$. In some studies large $(100 \times 8 \mathrm{~mm})$ columns were used, enabling column loadings of up to $10 \mathrm{mg}$ extract, and eluted at very low flow rates (down to $0.1 \mathrm{~mL} / \mathrm{min}$ ) to increase analyte residence time in the 60- $\mu$ L flow-cell used [27], [29], [30], [31]. Bringmann et al. used on-flow NMR typically operating in the isocratic mode with $\mathrm{CH}_{3} \mathrm{CN}$ and $\mathrm{D}_{2} \mathrm{O}$ mixtures at $0.7-0.8 \mathrm{~mL} /$ min, using a $250 \times 4.6 \mathrm{~mm}$ column and a $120-\mu \mathrm{L}$ flow-cell to detect naphthylisoquinoline alkaloids in crude plant extracts [32], [33], [34], [35]. Other continuous-flow studies reported in the literature include identification of constituents of a sesquiterpene lactone fraction from Vernonia fastigiata (Asteraceae) [36], use of the technique as guidance for pooling of separated glycolipid fractions [37], analysis of hop bitter acids extracted with supercritical $\mathrm{CO}_{2}$ [38], and identification of ecdysteroids of Silene otides (Caryophyllaceae) [39]. Further examples include analysis of natural products presents in beverages [40], [41], analysis of Streptomyces metabolites in culture broth [42], analysis of caro- 


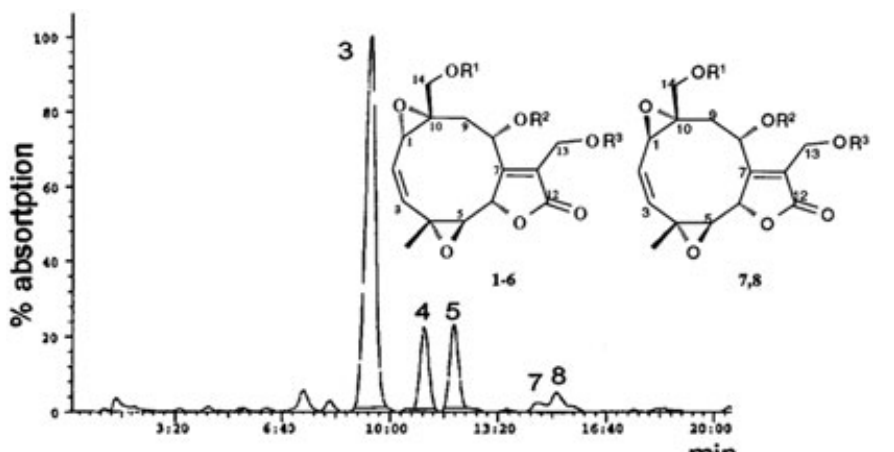

葛

Fig. 1 Bottom: Continuous-flow HPLC-NMR analysis of a sesquiterpene lactone fraction from Vernonia fastigata $\left(500 \mathrm{MHz}, 65-\mu \mathrm{L}\right.$ flow-cell, $\mathrm{C}_{18}$ column eluted with a $\mathrm{CH}_{3} \mathrm{CN}$ gradient in $\mathrm{D}_{2} \mathrm{O}$ at $0.9 \mathrm{~mL} / \mathrm{min}$, column loading $0.7 \mathrm{mg}$ ). Top: HPLC-UV chromatogram of the fraction. Reproduced from [36] by permission of the American Chemical Society. tenoid mixtures using $\mathrm{C}_{30}$ stationary phases, which have a high loading capacity [43], [44], investigation of a saponin fraction isolated from Bacopa monniera (Scrophulariaceae) [45], characterization of cardiac glycosides from in vitro cultured Isoplexis species (Scrophulariaceae) [46], analysis of cytotoxic fractions of Stauranthus perforatus (Rutaceae) [47], use of on-flow HPLCNMR to guide isolation of sesquiterpene lactones from Scalesia and Viguiera species (Asteraceae) [48], [49], [50], and analysis of a mixture of saponins isolated from starfish [51], [52]. The latter study [52], apart from providing structures of a number of starfish saponins, emphasized the importance of relaxation times in HPLC-NMR measurements. Examples of on-flow HPLC-NMR data are shown in Figs. 1 and $\mathbf{2}$.

In conclusion, on-flow measurements provide only preliminary information about extract or fraction components, normally restricted to major components. One advantage of on-flow HPLCNMR experiments is that they do not require any specialized hardware apart from the NMR flow-cell. Because other solvents have a reputation of being difficult to wash out from HPLC-NMR systems, acetonitrile is widely used as the organic component of mobile phases, but examples of the use of acetone [44] and methanol [45], [50] have been reported. Cases reported in the literature usually employ $\mathrm{D}_{2} \mathrm{O}-\mathrm{CH}_{3} \mathrm{CN}$ mixtures, using isocratic as well as gradient elution. In the latter case, the chemical shift of $\mathrm{CH}_{3} \mathrm{CN}$ changes with the composition of the mobile phase, which may affect spectral resolution and quality of solvent suppression. One study employed a gradient of $\mathrm{CD}_{3} \mathrm{CN}$ in $\mathrm{D}_{2} \mathrm{O}$ [39]. In order to avoid potentially deteriorating effects of magnetic susceptibility changes of the HPLC eluate during gradient elution, post-column solvent mixing to obtain a constant solvent composition in the NMR flow-cell was proposed [53]. Quantitative analysis by onflow NMR measurements has been discussed [54], [55].

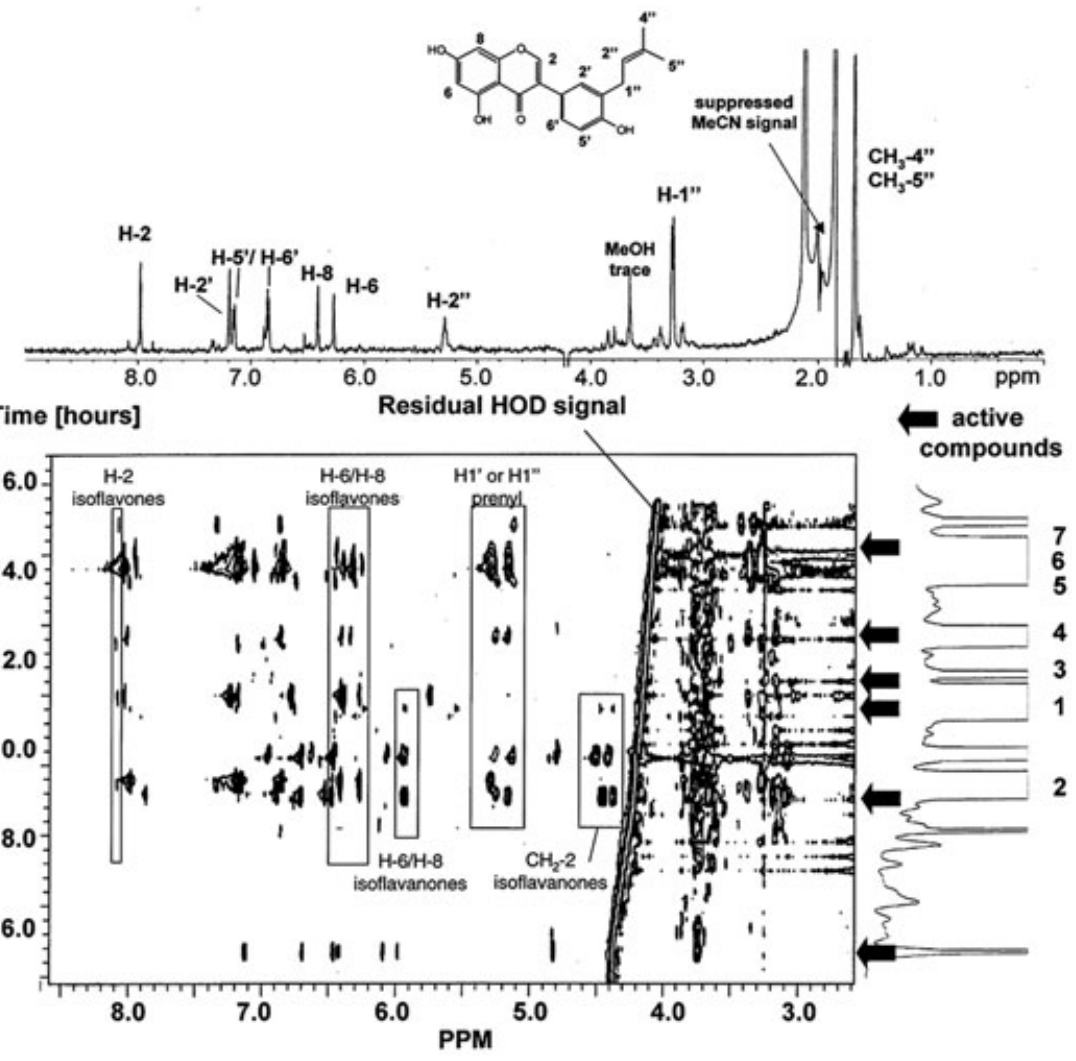

Fig. 2 Bottom: Continuous-flow HPLC-NMR contour plot obtained with a crude dichloromethane extract of Erythrina vogelii roots; horizontal and vertical axis represent ${ }^{1} \mathrm{H}$-NMR chemical shifts and HPLC retention times, respectively $(500 \mathrm{MHz}, 60-\mu \mathrm{L}$ flow-cell, $100 \times 8 \mathrm{~mm} \mathrm{C}_{18}$ column eluted with a $\mathrm{CH}_{3} \mathrm{CN}$ gradient in $\mathrm{D}_{2} \mathrm{O}$ at $\left.0.1 \mathrm{~mL} / \mathrm{min}\right)$. Top: Slice though the contour plot representing ${ }^{1} \mathrm{H}$-NMR spectrum of one extract component. Reproduced from [27] by permission of Elsevier. 


\section{Stopped-Flow Measurements}

2D NMR experiments, necessary for definitive structural assignments except in the simplest cases, are not feasible under continuous-flow conditions because of insufficient sensitivity. While extremely slow elution rates [56] can compensate for this limitation, the usual solution is to acquire spectra under stopped-flow conditions. Therefore, nearly all continuous-flow studies mentioned above also report stopped-flow experiments, either in order to improve the quality of ${ }^{1} \mathrm{H}$-NMR data or to perform 2D NMR experiments. It is perhaps fair to say that, in order to achieve un-

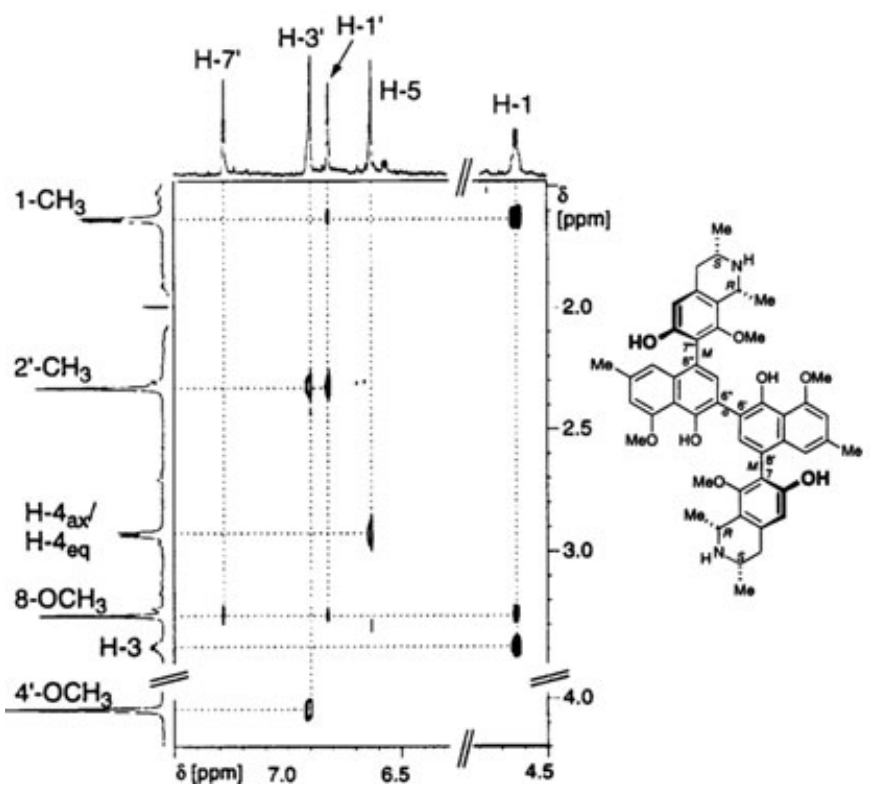

Fig. 3 Part of ROESY spectrum of a dimeric naphthylisoquinoline alkaloid from a pre-purified extract of Ancistrocladus griffithii, acquired in the stopped-flow mode $(600 \mathrm{MHz}, 60-\mu \mathrm{L}$ flow-probe, total acquisition time $17 \mathrm{~h}, 2 \mathrm{mg}$ of the extract injected to a $\mathrm{C}_{18}$ column eluted with a gradient of $\mathrm{CH}_{3} \mathrm{CN}$ in $\mathrm{D}_{2} \mathrm{O}$ ). Reproduced from [60] by permission of the American Chemical Society. iquely useful HPLC-NMR data, stopped-flow conditions must be involved. These conditions also allow enough time for careful optimization of field homogeneity and acquisition parameters.

Most studies use UV absorption to select peaks for stopped-flow NMR acquisition, although MS signals can also be used. The analyte can be kept for a very long time in the NMR flow-cell without problems caused by diffusion, allowing acquisition of very timeconsuming experiments. This is a function of the flow-probe design as well as the fact that peak elution volumes are usually larger than the total volume of the flow-cells used for HPLC-NMR, and thus thin tubing on both sides of the NMR flow-cell contains practically the same analyte concentrations as the cell. After all stopped-flow NMR experiments with a particular peak are completed, the flow may be restored, the next peak transferred to the NMR flow-cell, and so on. Diffusion-mediated band broadening of analytes still within the column may vary from very serious to insignificant, depending on the particular chromatographic conditions and the time period with stopped flow. Arguably, in the case of gradient elution, most of the analyte remaining at the column may be confined to a narrow region within the stationary phase at the column entrance, and sharp peaks may be eluted in spite of prolonged periods without flow. In other cases, stopped-flow conditions will result in a substantial decrease of concentration within elution bands and collapse closely spaced peaks, not only because of analyte diffusion but also because of diminishing solvent gradients across the column due to the diffusion of solvent molecules. In such cases one can acquire NMR data with different peaks from successive chromatographic runs (if no prohibitive limits to sample size exist). An analyte eluted as a large peak may contaminate the following, minor peaks because of the peak-broadening effect of the NMR flow-cell.

Numerous stopped-flow experiments with crude extracts or prepurified fractions have been reported in the literature. The chromatographic conditions used are generally the same as in onflow experiments, with $\mathrm{CH}_{3} \mathrm{CN}-\mathrm{D}_{2} \mathrm{O}$ mixtures as eluents, various

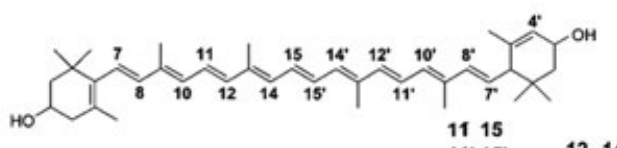

a) continuous-flow

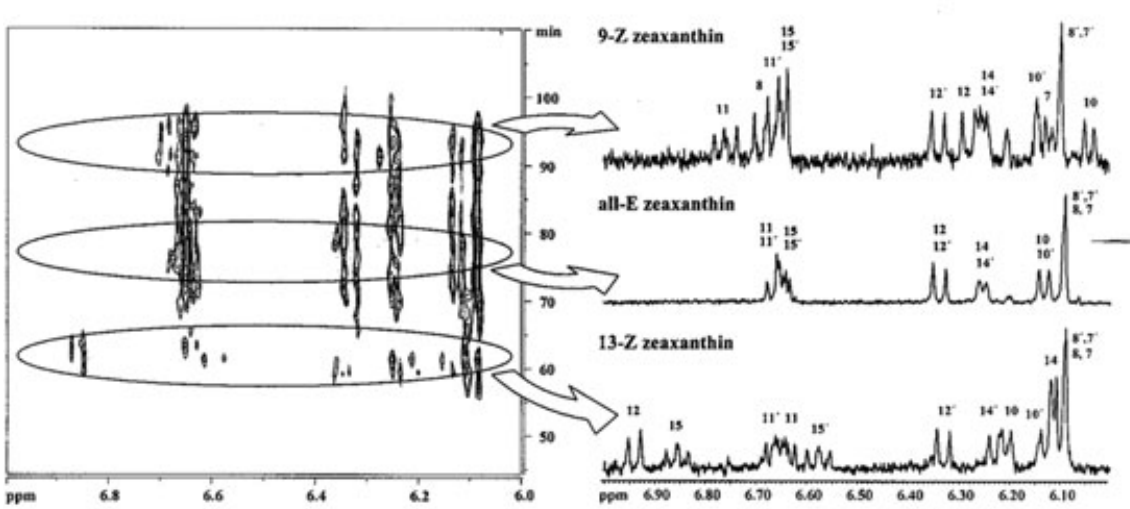

b) stopped-flow
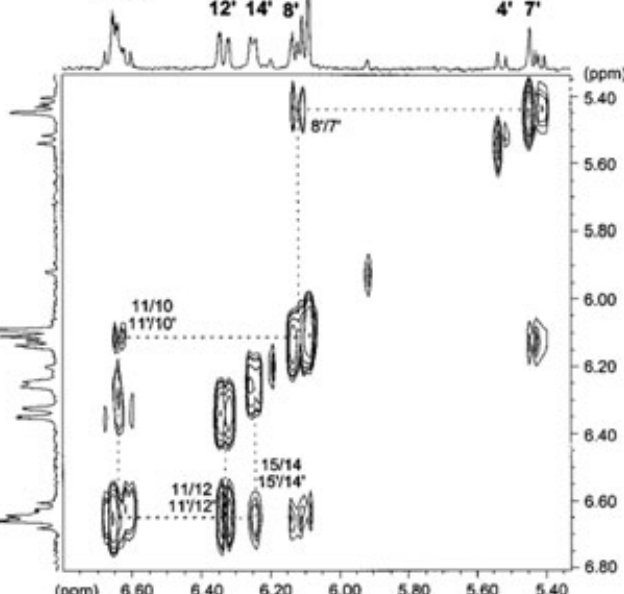

Fig. 4 Left: Continuous-flow HPLC-NMR analysis of a carotenoid mixture. Middle: Stopped-flow ${ }^{1} \mathrm{H}-\mathrm{NMR}$ spectra obtained from the same mixture $\left(600 \mathrm{MHz}, 120-\mu \mathrm{L}\right.$ flow-cell, $\mathrm{C}_{30}$ column eluted with acetone- $\mathrm{D}_{2} \mathrm{O}$ at $\left.1 \mathrm{~mL} / \mathrm{min}\right)$. Right: COSY spectrum recorded under stopped-flow conditions with a spinach extract (total acquisition time 25 h). Reproduced from [44] by permission of the American Chemical Society. 


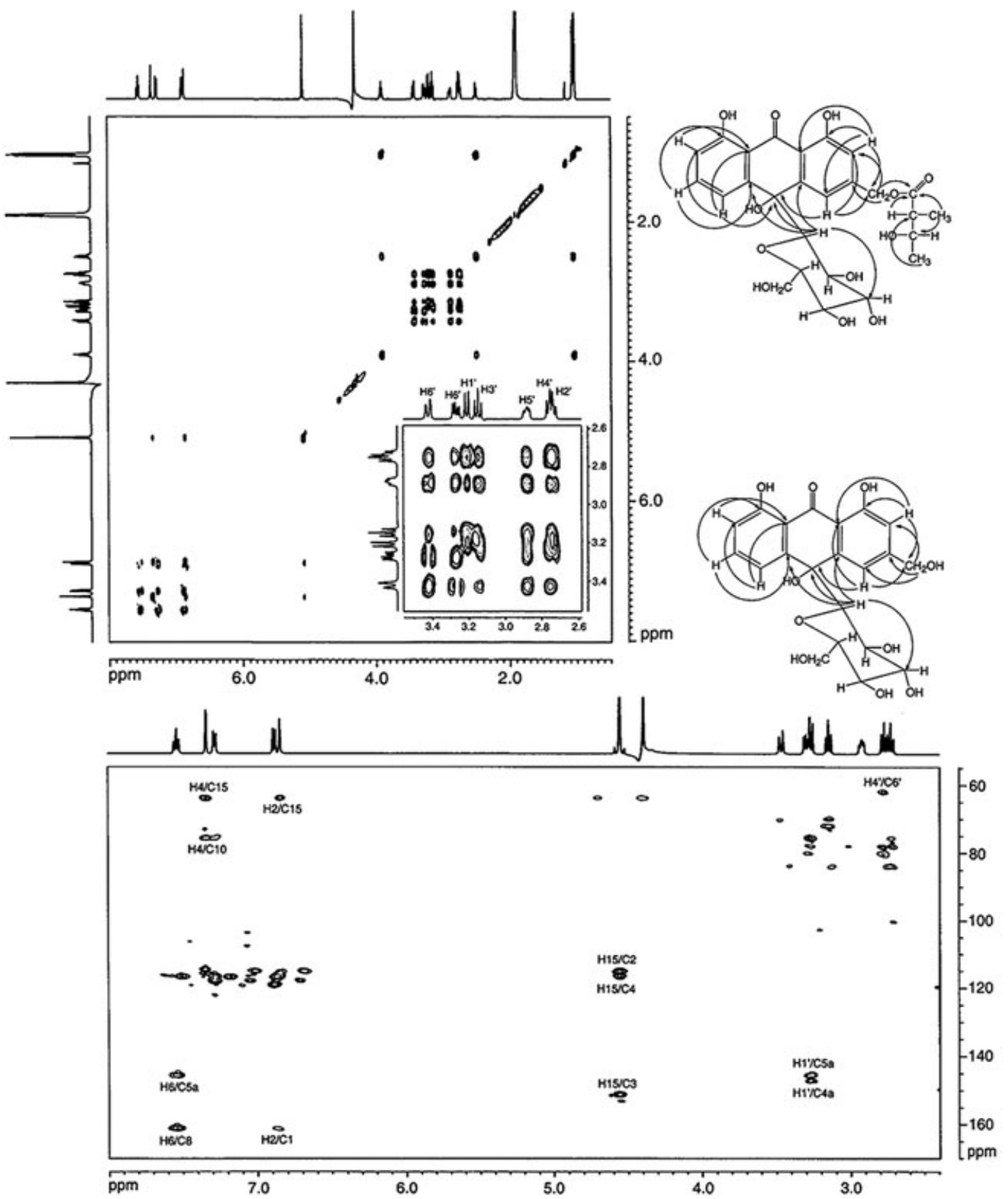

Fig. 5 Stopped-flow TOCSY (top) and HMBC (bottom) spectra acquired in the stopped-flow mode with Aloe littoralis leaf exudate $(500 \mathrm{MHz}$, $120-\mu \mathrm{L}$ cell, $\mathrm{C}_{18}$ column eluted with a $\mathrm{CH}_{3} \mathrm{CN}$ gradient in $\mathrm{D}_{2} \mathrm{O}$, $1.6 \mathrm{mg}$ mixture injected); because of the long data acquisition times, the spectra were acquired from separate injections. Reproduced from [79] by permission of John Wiley and Sons. sizes of analytical columns (typically $250 \times 4.6 \mathrm{~mm}$ ), and column loadings usually close to $1 \mathrm{mg}$. Bringmann et al. exploited the power of 2D NMR experiments acquired in the stopped-flow mode [32], [33], [34], [35], [57], [58], [59], [60], [61]. An example of a 2D NMR through-space correlation obtained in the stoppedflow mode with a fractionated extract is shown in Fig. 3. The previously mentioned $C_{30}$ reversed-phase material was applied in stopped-flow investigations of samples containing flavonoids [62], [63] and carotenoids [43], [44], [64] (Fig. 4). Other reported stopped-flow experiments deal with hop bitter acids [38], [65], starfish saponins [51], ecdysteroids of Silene otites (Caryophyllaceae) [39], [66], taxanes from Taxus species (Taxaceae) [67], metabolites from Anigozanthos species (Haemodoraceae) [68], [69], [70], lignans from Torreya jackii (Taxaceae) [71], extract of St. John's wort [72], Agromyces culture broth extract [73], a lignan glucoside from flax seed [74], flavonoids in Sorocea bomplandii (Moraceae) [75] and Trifolium pratense (Fabaceae) extract [76], protoberberine alkaloid fraction from Corydalis (Fumariaceae) cell cultures [77], [78], major metabolites of Aloe littoralis (Asphodelacaea) [79] (Fig. 5), flavonoid glycosides in transgenic tomatoes [80], sesame oil lignans [81], quinic acid derivatives from Fagara zanthoxyloides (Rutaceae) [82], betalain fraction from Hylocereus polyrhizus (Cactaceae) [83], phthalides from Ligusticum chuanxiong (Apiaceae) [84], and metabolites from several Chinese plants [85]. Moreover, various stopped-flow spectra were reported by the Hostettmann group [23], [24], [28], [29], [86], [87], [88], [89]. One study described use of a tetraethylammonium salt as a chromatographic ion-pairing agent, the signals of which had to be suppressed in stopped-flow HPLCNMR experiments [89]. Selective (1D) versions of 2D correlation experiments, which can provide crucial information in a very short time, have so far been only rarely used in HPLC-NMR studies of natural products [84], [90].

In addition to the simple, direct stop-flow experiments mentioned above, it is possible to stop the flow in regular intervals 
covering a part or the whole chromatogram. This time-slice stopped-flow experiment is an extension of the on-flow experiment with a very slow elution rate and has the advantage of being independent of other methods for detecting the location of chromatographic peaks; it was used for the analysis of beer constituents [40].

\section{Loop-Storage Technique}

In order to avoid potential problems with diffusion and pump start/stop effects on chromatograms, a device was developed that directs individual chromatographic peaks into capillary loops, where they are sealed and can be subsequently transferred into the NMR flow-probe in an arbitrary order. Since the loops are made of capillaries and not cavities as the NMR flow-cells, only minimal peak broadening occurs. Moreover, the flow-cell can be extensively washed between transfers of individual peaks stored in the loops, and thus analyte cross-contamination can be avoided. Therefore, this HPLC-NMR experiment has most of the advantages and no drawbacks inherent to the stopped-flow experiment, perhaps with the exception of increasing chance of decomposition of unstable constituents. However, only very few applications of this technique to natural products have been reported. One example describes the analysis of an artificial mixture of aporphine alkaloids [91]. Loop-storage HPLC-NMR analysis (including 2D NMR) of acetylated xylo-oligosaccharides using chromatographic separation with a $\mathrm{CH}_{3} \mathrm{OH}$ gradient in $\mathrm{D}_{2} \mathrm{O}$ was also reported [92]. Other examples include analysis of liquid food samples [40], [41], extract of apple peel [90], and sesquiterpene lactones [22]. The loop-storage technique can be regarded as intermediate between direct and indirect HPLC-NMR methods; although acquisition of NMR data can be physically and chronologically disconnected from the HPLC separation, the NMR data are still obtained in the solvent used for HPLC.

\section{Other Direct NMR Hyphenations}

In principle, NMR can be hyphenated with liquid-chromatographic methods other than HPLC. However, such techniques are in their infancy and not widely used. Since supercritical fluid (SF) extraction and chromatography (SFC) employing $\mathrm{CO}_{2}$ with various modifiers are broadly applicable within the natural products field, hyphenation of supercritical separations with NMR is of potential interest, especially because normal-phase separation mechanisms in SFC supplement those of reversed-phase HPLC. As $\mathrm{CO}_{2}$ does not contain hydrogen, the need of solvent suppression is limited to possible modifiers. The first report on SFCNMR hyphenation appeared already in 1988 [93] and the field was reviewed relatively recently [94]; genuine natural products applications have yet to be reported.

Since SFC is intermediate between gas and liquid chromatography, it should be mentioned that some early attempts of GCNMR hyphenation have been made [95], [96], [97], [98]. However, since modern GC separations are performed practically exclusively with capillary columns, the amount of material is insufficient for NMR, in addition to the purely technical difficulties that exist [94].
Several studies explored the use of superheated $\mathrm{D}_{2} \mathrm{O}$ as eluent for HPLC-NMR [99], [100]. Unlike supercritical water, which requires very high temperatures and is chemically aggressive, superheated water is a relatively inert eluent applicable for reversedphase HPLC; stopped-flow applications to ginger extract on a $C_{18}$ phase [101] and to vitamins on polystyrene-divinylbenzene [102] have been reported. NMR hyphenation with ion-exchange chromatography [103], centrifugal partition chromatography [104], gel permeation chromatography [105] and electro-driven separations [106] have been described.

Finally, it should be mentioned that although HPLC-NMR is capable of providing very detailed and unambiguous data on the molecular structure of natural products, it does not give any information about chirality. Therefore, hyphenation of HPLC with circular dichroism (HPLC-CD) is a useful supplement to HPLCNMR [35], [59], [60], [61], [107], [108]. A further extension of enantiomer characterization in connection with HPLC-NMR is the use of chiral HPLC columns [107] and HPLC-NMR of Moshertype esters [109], [110], [111]. The latter is an elegant way of combining the need of obtaining ${ }^{1} \mathrm{H}-\mathrm{NMR}$ chemical shift data with purification of microgram amounts of Mosher-type derivatives.

\section{New Trend: Indirect NMR Hyphenation}

Since its introduction in the late 1970s, HPLC-NMR has been developed from a scientific curiosity to a reliable technique that constitutes a crucial step towards rapid structure determination of natural products directly from mixtures (crude extracts). However, the common feature of the methods described in this review is that the HPLC side determines to a large extent the performance of the NMR part. Thus, NMR data are acquired at the analyte concentration delivered in the elution band and in the solvent used for HPLC. This is not optimal from the point of view of NMR spectroscopy due to various problems mentioned above and limits the range of suitable HPLC eluents. Moreover, the chemical shift data obtained with mixed solvents of varying composition are not directly comparable with the legacy chemical shift data on natural products available in the literature. The recently introduced HPLC-SPE-NMR technique, where solvent change between HPLC and NMR is achieved by use of a solidphase extraction (SPE) interface, creates a possibility of running reversed-phase HPLC separations as well as NMR acquisitions at optimal conditions and largely without mutual restrictions. Evidence accumulates that this new hyphenated technique offers dramatic improvements in the performance of structure elucidation of natural products directly from crude extracts [112], [113], [114], [115]. Detailed discussion of HPLC-SPE-NMR, together with presentation of other newest developments in NMR hyphenation, will be given in a forthcoming, second part of this review.

\section{References}

1 Bindseil KU, Jakupovic J, Wolf SD, Lavayre J, Leboul J, van der Pyl D. Pure compound libraries: a new perspective for natural product based drug discovery. Drug Discov Today 2001; 15: 40-7

2 Koehn FE, Carter GT. The evolving role of natural products in drug discovery. Nature Rev 2005; 4: 206-20 
3 Watanabe N, Niki E. Direct-coupling of FT-NMR to high-performance liquid-chromatography. Proc Jpn Acad Ser B 1978; 54: 194 - 9

4 Bayer E, Albert K, Nieder M, Grom E, Keller T. On-line coupling of high-performance liquid chromatography and nuclear magnetic resonance. J Chromatogr 1979; 186: 497-507

5 Haw JF, Glass TE, Hausler DW, Motell E, Dorn HC. Direct coupling of a liquid chromatograph to a continuous flow hydrogen nuclear magnetic resonance detector for analysis of petroleum and synthetic fuels. Anal Chem 1980; 52: 1135 -40

6 Bayer E, Albert K, Nieder M, Grom E, An Z. Examples of application of direct HPLC-NMR coupling with high resolution. Fresenius Z Anal Chem 1980; 404: 111 - 6

7 Buddrus J, Herzog H. Coupling of HPLC and NMR. 1. Analysis of flowing liquid-chromatographic fractions by proton magnetic resonance. Org Magn Res 1980; 13: $153-5$

8 Haw JF, Glass TE, Dorn HC. Continuous flow high field nuclear magnetic resonance detector for liquid chromatographic analysis of fuel samples. Anal Chem 1981; 53: 2327-32

9 Bayer E, Albert K, Nieder M, Grom E, Wolff G, Rindlisbacher M. Online coupling of liquid chromatography and high-field nuclear magnetic resonance spectrometry. Anal Chem 1982; 54: 1747-50

10 Albert K. LC-NMR: Theory and Experiment. In: On-line NMR and Related Techniques. Albert K, editor. Chichester: John Wiley \& Sons, 2002: pp 1-43

11 Cohen JS, Jaroszewski JW, Kaplan O, Ruiz-Cabello J, Collier SW. A history of biological applications of NMR spectroscopy. Progr Nucl Magn Res Spectr 1995; 28: $53-85$

12 Kovacs H, Moskau D, Spraul M. Cryogenically cooled probes - a leap in NMR technology. Progr Nucl Magn Res Spectr 2005; 46: 131 - 55

13 Yokota H. $4.5 \mathrm{~K}$ cooling system for a cryogenically cooled probe for a 920 MHz NMR magnet. AIP Conf Proc 2004; 710: 1826-33

14 Sidelmann UG, Braumann U, Hoffmann M, Spraul M, Lindon JC, Nicholson JK et al. Directly coupled $800 \mathrm{MHz}$ HPLC-NMR spectroscopy of urine and its application to the identification of the major phase II metabolites of tolfenamic acid. Anal Chem 1997; 69: 607-12

15 Corcoran O, Spraul M. LC-NMR-MS in drug discovery. Drug Discov Today 2003; 8: 624-31

16 Spraul M, Freund AS, Nast RE, Withers RS, Maas WE, Corcoran O. Advancing NMR sensitivity for LC-NMR-MS using a cryoflow probe: application to the analysis of acetaminophen metabolites in urine. Anal Chem 2003; 75: 1546 - 51

17 Smallcombe SH, Patt SL, Keifer PA. WET solvent suppression and its applications to LC NMR and high-resolution NMR spectroscopy. J Magn Res A 1995; 117: 295-303

18 Albert K, Nieder M, Bayer E, Spraul M. Continuous-flow nuclear magnetic resonance. J Chromatogr A 1985; 346: $17-24$

19 Griffiths L. Optimization of NMR and HPLC conditions for LC-NMR. Anal Chem 1995; 67: 4091 -5

20 Griffiths L. Optimization of liquid chromatography-NMR spectroscopy. II. Saturation and flow in on-flow liquid chromatography-NMR spectroscopy. Magn Res Chem 1997; 35: 257-61

21 Johnson S, Morgan ED, Wilson ID, Spraul M, Hofmann M. Photo-isomerization of azadirachtin studied by high performance liquid chromatography coupled to high field proton NMR spectroscopy. J Chem Soc Perkin Trans 1994; 1: 1499-502

22 Spring O, Buschmann H, Vogler B, Schilling EE, Spraul M, Hoffmann $M$. Sesquiterpene lactone chemistry of Zaluzania grayana from online LC-NMR measurements. Phytochemistry 1995; 39: 609-12

23 Wolfender JL, Rodrigues S, Hostettmann K, Hiller W. Liquid chromatography/ultraviolet/mass spectrometric and liquid chromatography/nuclear magnetic resonance spectroscopic analysis of crude extracts of Gentianaceae species. Phytochem Anal 1997; 8: 97 - 104

24 Garo E, Wolfender JL, Hostettmann K, Hiller W, Antus S, Mavi S. Prenylated flavones from Monotes engleri: on-line structure elucidation by LC/UV/NMR. Helv Chim Acta 1998; 81: 754-63

25 Cavin A, Potterat O, Wolfender JL, Hostettmann K, Dyatmyko W. Use of on-flow LC/ ${ }^{1} \mathrm{H}$ NMR for the study of an antioxidant fraction from Orophea enneandra and isolation of a polyacetylene, lignans, and a tocopherol derivative. J Nat Prod 1998; 61: 1497-501

26 Ioset JR, Wolfender JL, Marston A, Gupta MP, Hostettmann K. Identification of two isomeric meroterpenoid naphthoquinones from Cordia linnaei by liquid chromatography-mass spectrometry and liquid chromatography-nuclear magnetic resonance spectroscopy. Phytochem Anal 1999; 10: 137-42
27 Queiroz EF, Wolfender JL, Atindehou KK, Traore D, Hostettmann K. On-line identification of the antifungal constituents of Erythrina vogelii by liquid chromatography with tandem mass spectrometry, ultraviolet absorbance detection and nuclear magnetic resonance spectrometry combined with chromatographic micro-fractionation. J Chromatogr A 2002; 974: 123 -34

28 Wolfender JL, Verotta L, Belvisi L, Fuzzati N, Hostettmann K. Structural investigation of isomeric oxidized forms of hyperforin by HPLCNMR and HPLC-MS Phytochem Anal 2003; 14: 290 - 7

29 Zanolari B, Wolfender JL, Guilet D, Marston A, Queiroz EF, Paulo MQ et al. On-line identification of tropane alkaloids from Erythroxylum vacciniifolium by liquid chromatography-UV detection-multiple mass spectrometry and liquid chromatography-nuclear magnetic resonance spectrometry. J Chromatogr A 2003; 1020: 75-89

30 Waridel P, Wolfender JL, Lachavanne JB, Hostettmann K. ent-Labdane glycosides from the aquatic plant Potamogeton lucens and analytical evaluation of the lipophilic extract constituents of various Potamogeton species. Phytochemistry 2004; 65: 945-54

31 Waridel P, Wolfender JL, Lachavanne JB, Hostettmann K. Identification of the polar constituents of Potamogeton species by HPLC-UV with post-column derivatization, HPLC-MS ${ }^{\mathrm{n}}$ and HPLC-NMR, and isolation of a new ent-labdane diglycoside. Phytochemistry 2004; 65: 2401 - 10

32 Bringmann G, Ochse M, Herderich M, Günther C, Wolf K, Teltschik F et al. Isolation and structural elucidation of naphthylisoquinoline alkaloids. Pharm Pharmacol Lett 1998; 8: 1-4

33 Bringmann G, Günther C, Schlauer J, Rückert M. HPLC-NMR on-line coupling including the ROESY technique: direct characterization of naphthylisoquinoline alkaloids in crude plant extracts. Anal Chem 1998; 70: 2805-11

34 Bringmann G, Rückert M, Messer K, Schupp O, Louis AM. Acetogenic isoquinoline alkaloids. CXXI. Use of on-line high-performance liquid chromatography-nuclear magnetic resonance spectrometry coupling in phytochemical screening studies: rapid identification of metabolites in Dioncophyllum thollonii. J Chromatogr A 1999; 837: 267-72

35 Bringmann G, Messer K, Wohlfarth M, Kraus J, Dumbuya K, Rückert M. HPLC-CD on-line coupling in combination with HPLC-NMR and HPLC-MS/MS for the determination of the full absolute stereostructure of new metabolites in plant extracts. Anal Chem 1999; 71: 2678-86

36 Vogler B, Klaiber I, Roos G, Walter CU, Hiller W, Sandor P et al. Combination of LC-MS and LC-NMR as a tool for the structure determination of natural products. J Nat Prod 1998; 61: 175-8

37 Bäcker AE, Thorbert S, Rakotonirainy O, Hallberg EC, Olling A, Gustavsson $\mathrm{M}$ et al. Liquid chromatography "on-flow" ${ }^{1} \mathrm{H}$ nuclear magnetic resonance on native glycosphingolipid mixtures together with gas chromatography/mass spectrometry on the released oligosaccharides for screening and characterization of carbohydrate-based antigens from pig lungs. Glycoconjugate J 1999; 16: 45-58

38 Pusecker K, Albert K, Bayer E. Investigation of hop and beer bitter acids by coupling of high-performance liquid chromatography to nuclear magnetic resonance spectroscopy. J Chromatogr A 1999; 836: $245-52$

39 Wilson ID, Morgan ED, Lafont R, Shockor JP, Lindon JC, Nicholson JK et al. High performance liquid chromatography coupled to nuclear magnetic resonance spectroscopy and mass spectrometry applied to plant products: identification of ecdysteroids from Silene otites. Chromatographia 1999; 49: 374-8

40 Gil AM, Duarte IF, Godejohann M, Braumann U, Maraschin M, Spraul M. Characterization of the aromatic composition of some liquid foods by nuclear magnetic resonance spectrometry and liquid chromatography with nuclear magnetic resonance and mass spectrometric detection. Anal Chim Acta 2003; 488: 35-51

41 Duarte IF, Godejohann M, Braumann U, Spraul M, Gil AM. Application of NMR spectroscopy and LC-NMR/MS to the identification of carbohydrates in beer. J Agric Food Chem 2003; 51: 4847-52

42 Abel CBL, Lindon JC, Noble D, Rudd BAM, Sidebottom PJ, Nicholson JK. Characterization of metabolites in intact Streptomyces citricolor culture supernatants using high-resolution nuclear magnetic resonance and directly coupled high-pressure liquid chromatography-nuclear magnetic resonance spectroscopy. Anal Biochem 1999; 270: 220-30

43 Strohschein S, Rentel C, Lacker T, Bayer E, Albert K. Separation and identification of tocetrienol isomers by HPLC-MS and HPLC-NMR coupling. Anal Chem 1999; 71: 1780-5 
44 Dachtler M, Glaser T, Kohler K, Albert K. Combined HPLC-MS and HPLC-NMR on-line coupling for the separation and determination of lutein and zeaxanthin stereoisomers in spinach and in retina. Anal Chem 2001; 73: 667-74

45 Renukappa T, Roos G, Klaiber I, Vogler B, Kraus W. Application of high-performance liquid chromatography coupled to nuclear magnetic resonance spectrometry, mass spectrometry and bioassay for the determination of active saponins from Bacopa monniera Wettst. J Chromatogr A 1999; 847: 109-16

46 Gavidia I, Seitz HU, Perez-Bermudez P, Vogler B. LC-NMR applied to the characterization of cardiac glycosides from three micropropagated Isoplexis species. Phytochem Anal 2002; 13: 266-71

47 Setzer WN, Vogler B, Bates RB, Schmidt JM, Dicus CW, Nakkiew P et al. HPLC-NMR/HPLC-MS analysis of the bark extract of Stauranthus perforatus. Phytochem Anal 2003; 14: 54-9

48 Spring O, Heil N, Vogler B. Sesquiterpene lactones and flavanones in Scalesia species. Phytochemistry 1997; 46: 1369-73

49 Spring O, Zipper R, Klaiber I, Reeb S, Vogler B. Sesquiterpene lactones in Viguiera eriophora and Viguiera puruana (Heliantheae; Asteraceae). Phytochemistry 2000; 55: 255-61

50 Spring O, Zipper R, Reeb S, Vogler B, Da Costa FB. Sesquiterpene lactones and a myoinositol from glandular trichomes of Viguiera quinqueremis (Heliantheae; Asteraceae). Phytochemistry 2001; 57: 267-72

51 Sandvoss M, Pham LH, Levsen K, Preiss A, Mügge C, Wünsch G. Isolation and structural elucidation of steroid oligoglycosides from the starfish Asterias rubens by means of direct online LC-NMR-MS hyphenation and one- and two-dimensional NMR investigations. Eur J Org Chem, 2000: 1253-62

52 Sandvoss M, Weltring A, Preiss A, Levsen K, Wuensch G. Combination of matrix solid-phase dispersion extraction and direct on-line liquid chromatography-nuclear magnetic resonance spectroscopy-tandem mass spectrometry as a new efficient approach for the rapid screening of natural products: application to the total asterosaponin fraction of the starfish Asterias rubens. J Chromatogr A 2001; 917: 75-86

53 Jayawickrama DA, Wolters AW, Sweedler JV. Mobile phase compensation to improve NMR spectral properties during solvent gradients. Analyst 2003; 128: $421-6$

54 Godejohann M, Preiss A, Mügge C. Quantitative measurements in continuous-flow HPLC/NMR. Anal Chem 1998; 70: 590-5

55 Saito T, Iwasawa R, Ihara T, Kinugasa S, Nomura A, Maeda T. Evaluation of accuracy for the quantitative analysis using nuclear magnetic resonance as a detector of HPLC. Chromatography 2003; 24: $117-20$

56 Godejohann M, Preiss A, Mügge C, Wünsch G. Application of on-line HPLC- ${ }^{1} \mathrm{H}$ NMR to environmental samples: analysis of groundwater near former ammunition plants. Anal Chem 1997; 69: 3832 - 7

57 Bringmann G, Wohlfarth M, Heubes M. Observation of exchangeable protons by high-performance liquid chromatography-nuclear magnetic resonance spectroscopy and high-performance liquid chromatography-electrospray ionization mass spectrometry: a useful tool for the hyphenated analysis of natural products. J Chromatogr A 2000; 904: 243-9

58 Bringmann G, Rückert M, Saeb W, Mudogo V. Characterization of metabolites in plant extracts of Ancistrocladus likoko by high-performance liquid chromatography coupled on-line with ${ }^{1} \mathrm{H}$ NMR spectroscopy. Magn Res Chem 1999; 37: $98-102$

59 Edrada RA, Heubes M, Brauers G, Wray V, Berg A, Gräfe U et al. Online analysis of xestodecalactones A-C, novel bioactive metabolites from the fungus Penicillium $c f$. montanese and their subsequent isolation from the sponge Xestospongia exigua. J Nat Prod 2002; 65: 1598-604

60 Bringmann G, Wohlfarth M, Rischer H, Heubes M, Saeb W, Diem S et al. A photometric screening method for dimeric naphthylisoquinoline alkaloids and complete on-line structural elucidation of a dimer in crude plant extracts, by the LC-MS/LC-NMR/LC-CD triad. Anal Chem 2001; 73: $2571-7$

61 Bringmann G, Wohlfarth M, Rischer H, Schlauer J, Brun R. Extract screening by HPLC coupled to MS-MS, NMR, and CD: a dimeric and three monomeric naphthylisoquinoline alkaloids from Ancistrocladus griffithii. Phytochemistry 2002; 61: 195-204

62 Santos LC, Dachtler M, Andrade FDP, Albert K, Vilegas W. Application of HPLC-NMR coupling using $C_{30}$ phase in the separation and identification of flavonoids of taxonomic relevance. Fresenius J Anal Chem 2000; 368: $540-2$
63 Vilegas W, Vilegas JHY, Dachtler M, Glaser T, Albert K. Application of on-line $\mathrm{C}_{30}$ RP-HPLC-NMR for the analysis of flavonoids from leaf extract of Maytenus aquifolium. Phytochem Anal 2000; 11: 317-21

64 Glaser T, Lienau A, Zeeb D, Krucker M, Dachtler M, Albert K. Qualitative and quantitative determination of carotenoid stereoisomers in a variety of spinach samples by use of MSPD before HPLC-UV, HPLCAPCI-MS, and HPLC-NMR on-line coupling. Chromatographia Suppl 2003; 57: S19-25

65 Höltzel A, Schlotterbeck G, Albert K, Bayer E. Separation and characterization of hop bitter acids by HPLC- ${ }^{1} \mathrm{H}$ NMR coupling. Chromatographia 1996; 42: 499-505

66 Wilson ID, Morgan ED, Lafont R, Wright B. High-performance liquid chromatography coupled to nuclear magnetic resonance spectroscopy - application to the ecdysteroids of Silene otites. J Chromatogr A 1998; 799: 333-6

67 Schneider B, Zhao Y, Blitzke T, Schmitt B, Nookandeh A, Sun X, Stöckigt J. Taxane analysis by high performance liquid chromatographynuclear magnetic resonance spectroscopy of Taxus species. Phytochem Anal 1998; 9: 237-44

68 Hölscher D, Schneider B. HPLC-NMR analysis of phenylphenalenones and a stilbene from Anigozanthos flavidus. Phytochemistry 1999; 50: $155-61$

69 Schmitt B, Schneider B. Dihydrocinnamic acids are involved in the biosynthesis of phenylphenalenones in Anigozanthos preissii. Phytochemistry 1999; $52: 45-53$

70 Schmitt B, Schneider B. Phenylpropanoid interconversion in Anigozanthos preissii observed by high-performance liquid chromatography-nuclear magnetic resonance spectroscopy. Phytochem Anal 2001; $12: 43-7$

71 Zhao Y, Nookandeh A, Schneider B, Sun X, Schmitt B, Stöckigt J. Lignans from Torreya jackii identified by stopped-flow high-performance liquid chromatography-nuclear magnetic resonance spectroscopy. J Chromatogr A 1999; 837: 83-91

72 Hansen SH, Jensen AG, Cornett C, Bjørnsdottir I, Taylor S, Wright B et al. High-performance liquid chromatography on-line coupled to high-field NMR and mass spectrometry for structure elucidation of constituents of Hypericum perforatum L. Anal Chem 1999; 71: $5235-41$

73 Kleinwächter P, Martin K, Groth I, Dornberger K. Use of coupled HPLC/ ${ }^{1} \mathrm{H}$ NMR and HPLC/ESI-MS for the detection and identification of $(2 E, 4 Z)$-decanedioic acid from a new Agromyces species. J High Res Chromatogr 2000; 23: 609-12

74 Fritsche J, Angoelal R, Dachtler M. On-line liquid chromatographynuclear magnetic resonance spectroscopy-mass spectrometry coupling for the separation and characterization of secoisolariciresinol diglucoside isomers in flaxseed. J Chromatogr 2002; 972: 195-203

75 Andrade FDP, Santos LC, Datchler M, Albert K, Vilegas W. Use of online liquid chromatography-nuclear magnetic resonance spectroscopy for the rapid investigation of flavonoids from Sorocea bomplandii. J Chromatogr A 2002; 953: 287-91

76 De Rijke E, de Kandet F, Ariese F, Brinkman UAT, Gooijer C. Liquid chromatography coupled to nuclear magnetic resonance spectroscopy for the identification of isoflavone glucoside malonates in $T$. pratense L. leaves. J Sep Sci 2004; 27: 1061 - 70

77 Iwasa K, Kuribayashi A, Sugiura M, Moriyasu M, Lee D-U, Wiegrebe W. LC-NMR and LC-MS analysis of 2,3,10,11-oxygenated protoberberine metabolites in Corydalis cell culture. Phytochemistry 2003; 64: $1229-38$

78 Iwasa K, Kuribayashi A, Sugiura M, Nishiyama Y, Ichimaru M, Moriyasu $\mathrm{M}$ et al. Bioconversion studies in cultured cells of Corydalis species. Pharmazie 2004; 59: 480-3

79 Karagianis G, Vljoen A, Waterman PG. Identification of major metabolites in Aloe littoralis by high-performance liquid chromatography-nuclear magnetic resonance spectroscopy. Phytochem Anal 2003; $14: 275-80$

80 Le Gall G, DuPont MS, Mellon FA, Davis AL, Collins GJ, Verhoeyen ME et al. Characterization and content of flavonoid glycosides in genetically modified tomato (Lycopersicon esculentum) fruits. J Agric Food Chem 2003; $51: 2438-46$

81 Dachtler M, van de Put FHM, van Stijn F, Beindorff CM, Fritsche J. Online LC-NMR-MS characterization of sesame oil extracts and assessment of their antioxidant activity. Eur J Lipid Sci Technol 2003; 105: $488-96$ 
82 Ouattara B, Angenot L, Guissou P, Fondu P, Dubois J, Frederich M et al. LC/MS/NMR analysis of isomeric divanilloylquinic acids from the root bark of Fagara zanthoxyloides Lam. Phytochemistry 2004; 65: 1145 51

83 Stintzing FC, Conrad J, Klaiber I, Beifuss U, Carle R. Structural investigations on betacyanin pigments by LC NMR and 2D NMR spectroscopy. Phytochemistry 2004; 65: 415-22

84 Zschocke S, Klaiber I, Bauer R, Vogler B. HPLC-coupled spectroscopic techniques (UV, MS, NMR) for the structure elucidation of phthalides from Ligusticum chuanxiong. Mol Diver 2005; 9: 33 -9

85 Wang Y, He W, Li X, Li B, Liu X, Lin M. Application of LC-NMR and nano probe technology in natural products. Chin J Magn Res 2002; 19: $312-25$

86 Rodriguez S, Wolfender JL, Hostettmann K, Stoeckli-Evans H, Gupta MP. Monoterpene dimers from Lisianthius seemannii. Helv Chim Acta 1998; 81: $1393-403$

87 Schaller F, Wolfender JL, Hostettmann K, Mavi S. New antifungal 'quinone methide' diterpenes from Bobgunnia madagascariensis and study of their interconversion by LC/NMR. Helv Chim Acta 2001; 84: $222-9$

88 Cogne AL, Queiroz EF, Wolfender JL, Marston A, Mavi S, Hostettmann $\mathrm{K}$. On-line identification of unstable catalpol derivatives from Jamesbrittenia fodina by LC-MS and LC-NMR. Phytochem Anal 2003; 14: $67-73$

89 Ramm M, Wolfender JL, Queiroz EF, Hostettmann K, Hamburger M. Rapid analysis of nucleotide-activated sugars by high-performance liquid chromatography coupled with diode-array detection, electrospray ionization mass spectrometry and nuclear magnetic resonance. J Chromatogr A 2004; 1034: 139-48

90 Lommen A, Godejohann M, Venema DP, Hollman PCH, Spraul M. Application of directly coupled HPLC-NMR-MS to the identification and confirmation of quercetin glycosides and phloretin glycosides in apple peel. Anal Chem 2000; 72: 1793-7

91 Tseng LH, Braumann U, Godejohann M, Lee SS, Albert K. Structure identification of aporphine alkaloids by on-line coupling of HPLCNMR with loop storage. J Chin Chem Soc 2000; 47: 1231 -6

92 Kabel MA, de Waard P, Schols HA, Voragen AGJ. Location of $O$-acetyl substituents in xylo-oligosaccharides obtained from hydrothermally treated Eucalyptus wood. Carbohydr Res 2003; 338: 69-77

93 Allen LA, Glass TE, Dorn HC. Direct monitoring of supercritical fluids and supercritical chromatographic separations by proton nuclear magnetic resonance. Anal Chem 1988; 60: 390-4

94 Fischer H, Albert K. SFC-NMR and SFE-NMR. In: On-line LC-NMR and Related Techniques. Albert K, editor. Chichester: John Wiley \& Sons, 2002: pp 195-218

95 Brame Jr EG. Combining gas chromatography with nuclear magnetic resonance spectrometry. Anal Chem 1965; 37: $1183-4$

96 Tsuda T, Ojika Y, Izuda M, Fujishima I, Ishii D. The combination of gas chromatography and nuclear magnetic resonance spectroscopy. J Chromatogr 1972; 69: $194-5$

97 Buddrus J, Herzog H. Coupling of chromatography and NMR. 3. Study of flowing gas-chromatographic fractions by proton magnetic-resonance. Org Magn Res 1981; 15: 211 - 3

98 Herzog H, Buddrus J. Coupling of chromatography and NMR. Part 5. Analysis of high-boiling gas-chromatographic fractions by online nuclear magnetic-resonance. Chromatographia 1984; 18: 31 -3

99 Smith RM, Chienthavorn O, Wilson ID, Wright B. Superheated deuterium oxide reversed-phase chromatography coupled to proton nuclear magnetic resonance spectroscopy. Anal Commun 1998; 35: 261 - 3
${ }^{100}$ Smith RM, Chienthavorn O, Wilson ID, Wright B, Taylor SD. Superheated heavy water as the eluent for HPLC-NMR and HPLC-NMR-MS of model drugs. Anal Chem 1999; 71: 4493-7

101 Saha S, Smith RM, Lenz E, Wilson ID. Analysis of a ginger extract by high-performance liquid chromatography coupled to nuclear magnetic resonance spectroscopy using superheated deuterium oxide as the mobile phase. J Chromatogr A 2003; 991: 143-50

${ }^{102}$ Chienthavorn O, Smith RM, Saha S, Wilson ID, Wright B, Taylor SD et al. Superheated water chromatography-nuclear magnetic resonance spectroscopy and mass spectrometry of vitamins. J Pharm Biomed Anal 2004; 36: 477-82

${ }^{103}$ Dear GJ, Plumb RS, Sweatman BC, Parry PS, Roberts AD, Lindon JC et al. Use of directly coupled ion-exchange liquid chromatography-mass spectrometry and liquid chromatography-nuclear magnetic resonance spectroscopy as a strategy for polar metabolite identification. J Chromatogr A 2000; 748: 295-309

104 Spraul M, Braumann U, Renault JH, Thepenier P, Nuzillard JM. Nuclear magnetic resonance monitoring of centrifugal partition chromatography in pH-zone-refining mode. J Chromatogr A 1997; 766: 255 - 60

105 Händel H, Albert K. GPC-NMR Coupling. In: On-line LC-NMR and Related Techniques. Albert K, editor. Chichester: John Wiley \& Sons, 2002: pp $182-94$

106 Schefer AB, Albert K. Capillary Separation Techniques. In: On-line LCNMR and Related Techniques. Albert K, editor. Chichester: Wiley \& Sons, 2002: pp 238-46

${ }^{107}$ Mistry N, Roberts AD, Tranter GE, Francis P, Barylski I, Ismail IM et al. Directly coupled chiral HPLC-NMR and HPLC-CD spectroscopy as complementary methods for structural and enantiomeric isomer identification: application to atracurium besylate. Anal Chem 1999; 71: $2838-43$

108 Bringmann G, Lang G. Full absolute stereochemistry of natural products directly from crude extracts: the HPLC-MS/MS-NMR-CD 'triad'. Prog Mol Subcell Biol 2003; 37: 87-116

109 Seco JM, Tseng LH, Godejohann M, Quinoa E, Riguera R. Simultaneous enantioresolution and assignment of absolute configuration of secondary alcohols by directly coupled HPLC-NMR of 9-AMA esters. Tetrahedron: Asymmetry 2002; 13: 2149-53

110 Queiroz EF, Wolfender JL, Raoelison G, Hostettmann K. Determination of the absolute configuration of 6-alkylated $\alpha$-pyrones from Ravensara crassifolia by LC-NMR. Phytochem Anal 2003; 14: 34-9

111 Guilet D, Guntern A, Ioset JR, Queiroz EF, Ndjoko K, Foggin CM et al. Absolute configuration of a tetrahydrophenanthrene from Heliotropium avalifolium by LC-NMR of its Mosher esters. J Nat Prod 2003; 66: $17-20$

112 Exarchou V, Godejohann M, van Beek TA, Gerothanassis IP, Vervoort J. LC-UV-solid-phase extraction-NMR-MS combined with a cryogenic flow probe and its application to the identification of compounds present in Greek oregano. Anal Chem 2003; 75: 6288-94

113 Clarkson C, Stærk D, Hansen SH, Jaroszewski JW. Hyphenation of solid-phase extraction with liquid chromatography and nuclear magnetic resonance: application of HPLC-DAD-SPE-NMR to identification of constituents of Kanahia laniflora. Anal Chem 2005; 77: 3547 -53

114 Lambert M, Stærk D, Hansen SH, Jaroszewski JW. HPLC-SPE-NMR hyphenation in natural products research: optimization of analysis of Croton membranaceus extract. Magn Res Chem, in press

${ }^{115}$ Lambert M, Stærk D, Hansen SH, Sairafianpour M, Jaroszewski JW. Rapid extract dereplication using HPLC-SPE-NMR: analysis of isoflavonoids from Smirnowia iranica. J Nat Prod, in press 